\title{
Kinetic Study on Air Regeneration of Industrial MTO Catalyst
}

Jianping Zhao ${ }^{\mathrm{a}, \mathrm{b}}$, Jibin Zhou ${ }^{\mathrm{a}}$, Mao Ye ${ }^{\mathrm{a}, *}$, Zhongmin Liu ${ }^{\mathrm{a}}$

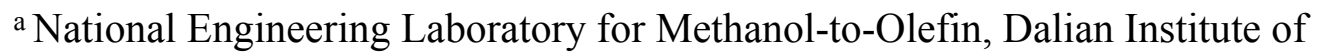

Chemical Physics, Chinese Academy of Sciences, Dalian, China, 116023

b University of Chinese Academy of Sciences, Beijing, China, 100049

\section{Corresponding Address}

*E-mail: maoye@dicp.ac.cn 


\section{The introduction of model-free methods}

\subsection{Flynn-Wall-Ozawa's method (FWO).}

This method 1,2 developed by Flynn, Wall and Ozawa was derived from on Doyle's approximation ${ }^{3}$. And it is based on the following expression:

$$
\ln \beta_{i}=\ln \left[A h\left(P_{O_{2}}\right) E_{x} / R g(x)\right]-5.331-1.052^{E_{x} / R T_{x}}
$$

Thus, from the slope of $\ln \beta$ against $1 / T$, the value of apparent activation energy at a constant value of coke conversion $x$.

\subsection{Kissinger-Akahira-Sunose's method (KAS).}

The $\mathrm{KAS}^{1,4}$ method developed by Kissinger, Akahira and Sunose is derived CoatsRedfern approximation ${ }^{5}$, which can be simplified as

$$
\ln \left(\beta_{i} / T_{x}^{2}\right)=\ln \left[A h\left(P_{O_{2}}\right) E_{x} / R g(x)\right]-E_{x} / R T_{x}
$$

For a given coke conversion $x, E$ can be estimated from the achieved slope of $\ln \left(\beta / T^{2}\right)$ against $1 / \mathrm{T}$.

\subsection{Vyazovkin method.}

According to Vyazovkin method, for numerous different heating rates, the apparent activation energy can be calculated via minimizing Eq. $8^{1,6}$ :

$$
\sum_{i=1}^{n} \sum_{j \neq i}^{n}\left[I\left(E_{x}, T_{x, i}\right) \beta_{j}\right] /\left[\mathrm{I}\left(E_{x}, T_{x, j}\right) \beta_{i}\right]=\min
$$

with $I\left(E_{x}, T_{x}\right)=\int_{0}^{T_{x}} \exp \left[-E_{x} /(R T)\right] d T$.

\subsection{Friedman method.}

Friedman method ${ }^{1,7}$ is a type of differential model-free method. It is derived from the logarithm form of Eq.4.

$$
\ln \left[\beta_{i}(d x / d T)\right]=\ln \left[A f(x) h\left(P_{O_{2}}\right)\right]-E_{x} / \mathrm{R} T
$$


For a given coke conversion $x$, the value of $E$ can be achieved from the slope of $\ln$ $[\beta(d x / d T)]$ versus $1 / T$.

\section{Combustion activation energy for aging MTO catalyst}

Table S1 shows the evolution of combustion activation energy for aging treatment industrial MTO catalyst sample at various conversion of the coke. From table S1, we can observe mean values of $E$ for FWO, KAS, Friedman and Vyazovkin method are $157.3,143,156.8$ and $143.6 \mathrm{~kJ} / \mathrm{mol}$, respectively. And the mean value of for four model-free methods is $150.1 \mathrm{~kJ} / \mathrm{mol}$, which is high than that of without aging catalyst sample $(141.1 \mathrm{~kJ} / \mathrm{mol})$. This is due to the effect of aging treatment, which has an influence on the ratio of $\mathrm{H} / \mathrm{C}^{8}$.

Table S1. Comparison of the activation energies $(E)$ at different conversion of coke for aging catalyst sample by FWO, KAS, Friedman and Vyazovkin methods.

\begin{tabular}{|c|c|c|c|c|c|c|c|}
\hline & FWO & & KAS & & Friedman & & Vyazovkin \\
\hline$x$ & $\mathrm{E}(\mathrm{kJ} / \mathrm{mol})$ & $\mathrm{R}^{2}$ & $\mathrm{E}(\mathrm{kJ} / \mathrm{mol})$ & $\mathrm{R}^{2}$ & $\mathrm{E}(\mathrm{kJ} / \mathrm{mol})$ & $\mathrm{R}^{2}$ & $\mathrm{E}(\mathrm{kJ} / \mathrm{mol})$ \\
\hline 0.1 & 141.1 & 0.9991 & 128.0 & 0.9989 & 139.9 & 0.9999 & 128.6 \\
\hline 0.2 & 148.9 & 0.9996 & 135.3 & 0.9995 & 142.0 & 0.9997 & 135.9 \\
\hline 0.3 & 152.3 & 0.9993 & 138.4 & 0.9991 & 157.2 & 0.9987 & 139.0 \\
\hline 0.4 & 155.4 & 0.9991 & 141.3 & 0.9989 & 148.9 & 0.9984 & 141.9 \\
\hline 0.5 & 158.3 & 0.9992 & 143.9 & 0.9988 & 149.6 & 0.9971 & 144.6 \\
\hline 0.6 & 161.5 & 0.9991 & 146.9 & 0.9977 & 164.8 & 0.9971 & 147.6 \\
\hline 0.7 & 166.3 & 0.9988 & 151.5 & 0.9962 & 174.2 & 0.9995 & 152.1 \\
\hline 0.8 & 173.5 & 0.9981 & 158.5 & 0.9991 & 178.1 & 0.9997 & 159.1 \\
\hline
\end{tabular}




\begin{tabular}{lllll} 
Average & 157.3 & 143.0 & 156.8 & 143.6 \\
\hline
\end{tabular}

\section{Reference}

(1) Vyazovkin, S.; Burnham, A. K.; Criado, J. M.; Perez-Maqueda, L. A.; Popescu, C.; Sbirrazzuoli, N. ICTAC Kinetics Committee recommendations for performing kinetic computations on thermal analysis data. Thermochim. Acta. 2011, 520, 1.

(2) Flynn, J. H.; Wall, L. A. A quick, direct method for the determination of activation energy from thermogravimetric data. J. Polym. Sci., Part B: Polym. Lett. 1966, 4, 323.

(3) Doyle, C. D. Series Approximations to Equation of Thermogravimetric Data. Nature 1965, 207, 290.

(4) Kissinger, H. E. Reaction Kinetics in Differential Thermal Analysis. Anal. Chem. 1957, $29,1702$.

(5) Coats, A. W.; Redfern, J. P. Kinetic Parameters from Thermogravimetric Data. Nature 1964, 201, 68.

(6) Vyazovkin, S. Advanced isoconversional method. J. Therm. Anal. Calorim. 1997, 49, 1493.

(7) Friedman, H. L. Kinetics of thermal degradation of char-forming plastics from thermogravimetry. Application to a phenolic plastic. J. Polym. Sci., Part C: Polym. Symposia. 1964, 6, 183.

(8) Aguayo, A. T.; Gayubo, A. G.; Atutxa, A.; Olazar, M.; Bilbao, J. Regeneration of a catalyst based on a SAPO-34 used in the transformation of methanol into olefins. J. Chem. Technol. Biotechnol. 1999, $74,1082$. 